\title{
Differentiation of Astrocytes and Oligodendrocytes from Germinal Matrix Cells in Primary Culture
}

\author{
James E. Goldman, Sharon Scott Geier, and Michio Hirano \\ Departments of Pathology (Neuropathology) and Neuroscience, Albert Einstein College of Medicine, \\ Bronx, New York 10461
}

Primary cultures derived from neonatal rat forebrain grow almost entirely as glial cultures, with a large astrocytic preponderance and smaller numbers of oligodendrocytic cells. Although both astrocytic and oligodendrocytic characteristics are acquired in vitro, the origins of both types of glia in primary cultures have not been determined. We tested the hypothesis that glia differentiate in vitro from immature neuroectodermal cells by following the fate of germinal zone cells in primary cultures. A monoclonal antibody that binds GD3 ganglioside was used as a marker for cells of the subventricular zone (SVZ), since antibody binding in newborn rat forebrain could be detected by immunofluorescence only in the SVZ of newborn rats (Goldman et al., 1984). We followed the expression of glial fibrillary acidic protein (GFAP), an astrocytic marker; galactocerebroside (GC), an oligodendrocytic marker; and GD3 during the first several weeks of culture. Both GFAP and GC expression were first detected in cells that bound the GD3 antibody. Astrocytes developed during the first week in vitro; eventually, they lost the ability to bind the GD3 antibody and most became GD3-/GFAP + cells. In high-density cultures, a population of small cells that resided on top of the astrocytic monolayer retained GD3 expression. GC-antibody binding was first observed in these cells of the upper layer, although it was not readily apparent until the second week of culture. Few GC + cells were seen in cultures grown at low density, however. When these small, process-bearing GD3 + cells were isolated by rotary agitation from high-density cultures at $7 \mathrm{~d}$ in vitro and subcultured in the presence of $20 \%$ fetal calf serum, they did not acquire an oligodendrocytic character, but rapidly began to express the astrocyte marker, GFAP. Germinal zone cells can thus give rise to both astrocytic and oligodendrocytic cells in primary culture. The developmental fate of glial precursor cells can be manipulated, however. The isolation and controlled differentiation of immature neuroectodermal cells should provide an important approach to illuminating detailed steps in gliogenesis.

Early postnatal development of the rodent CNS is remarkable for the rapid appearance of astrocytes and oligodendrocytes. Developmental studies indicate that the glia in subcortical white matter, including the corpus callosum, are derived from immature neuroectodermal cells of the subventricular zone, the major germinal zone of the cerebral hemispheres (Altman, 1966;

\footnotetext{
Received Dec. 28, 1984; revised July 15, 1985; accepted July 17, 1985.

This work was supported by USPHS Grant NS17125 and an NIH TeacherInvestigator Award (NS 00524) to J.E.G. The authors thank Drs. Kenneth Lloyd and Robert Yu for the anti-GD3 antibody and Drs. Kay Fields and William Norton for helpful discussions.

Correspondence should be sent to Dr. James E. Goldman at the Department of Pathology (Neuropathology), Albert Einstein College of Medicine, 1300 Morris Park Ave., Bronx, NY 10461.
}

Copyright (C) 1986 Society for Neuroscience $0270-6474 / 86 / 010052-09 \$ 02.00 / 0$
Imamoto et al., 1978; Privat and Leblond, 1972). Although much is known about morphological changes during glial differentiation, little is known about the specific molecular changes that immature cells undergo in acquiring glial characteristics, or about the stimuli that induce specific glial differentiation. Studies of dissociated cell cultures from neonatal and young rodent CNS represent one experimental approach to understanding the details of glial development. Recent studies with cultures derived from young optic nerve have revealed the developmental potential of a population of immature cells. This population, recognized by the monoclonal antibody A2B5, is able to differentiate in vitro along astrocytic or oligodendrocytic lines (Raff et al., 1983b; Temple and Raff, 1985), the former lineage prompted by serum, the latter by a serum-free, chemically defined medium.

In this study, we have used a monoclonal antibody directed against GD3 ganglioside to trace glial differentiation in cultures from neonatal forebrain. We have recently found that GD3 ganglioside is a characteristic glycolipid component of germinal zone cells, both neuronal and glial precursors in the developing rat CNS (Goldman et al., 1984). In newborn and young rat hemispheres, GD3 could be detected in cells of the subventricular zone (SVZ), the major hemispheric germinal plate. Since newborn telencephalon constitutes the starting cell population for the primary cultures that we and others have worked with, we considered the possibility of using the anti-GD3 antibody to define those cells derived from the SVZ in dissociated cell cultures and to ask whether these cells acquire in vitro any of the characteristics of mature glia. If so, this would point to SVZ cells as a source of glia in primary forebrain cultures and would also indicate that gliogenesis from germinal zone cells could be studied in vitro. This strategy would be possible if cells retained GD3 expression, at least transiently, while they acquired components of mature glia. Our results indicate that they do, and that these cells represent the major source of both astrocytes and oligodendrocytes in forebrain primary cultures.

\section{Materials and Methods}

\section{Cell cultures}

Primary cultures were established from newborn Wistar rat forebrains (Chiu and Goldman, 1984). Forebrains, stripped of meninges and dissected from diencephalon, were minced and then incubated at $37^{\circ} \mathrm{C}$ in Hank's balanced salt solution with $0.25 \%$ trypsin for $10 \mathrm{~min}$, resuspending the suspension after $5 \mathrm{~min}$. After inhibiting the trypsin with calf serum, the suspension was again disrupted with a pipette and filtered through a $165 \mu \mathrm{m}$ and then a $75 \mu \mathrm{m}$ Nitex mesh. Cells were collected by centrifugation at $200 \times g$ and seeded onto poly-L-lysine-coated plastic dishes ( $55 \mathrm{~mm}$ diameter) or T-flasks $\left(75 \mathrm{~cm}^{2}\right.$ area) at $0.4 \times 10^{5}$ (lowdensity) or $2.4 \times 10^{5}$ (high-density) cells $/ \mathrm{cm}^{2}$. Cultures were grown at $37^{\circ} \mathrm{C}$ in a humidified atmosphere of $5 \% \mathrm{CO}_{2}$ in a medium containing (per $100 \mathrm{ml}$ ) $10 \mathrm{ml}$ MEM with Earle's salts $(10 \times), 20 \mathrm{ml}$ fetal calf serum, $4 \mathrm{ml}$ MEM vitamins, $2 \mathrm{ml}$ MEM amino acids $(100 \times), 1.8 \mathrm{ml} 30 \%$ 

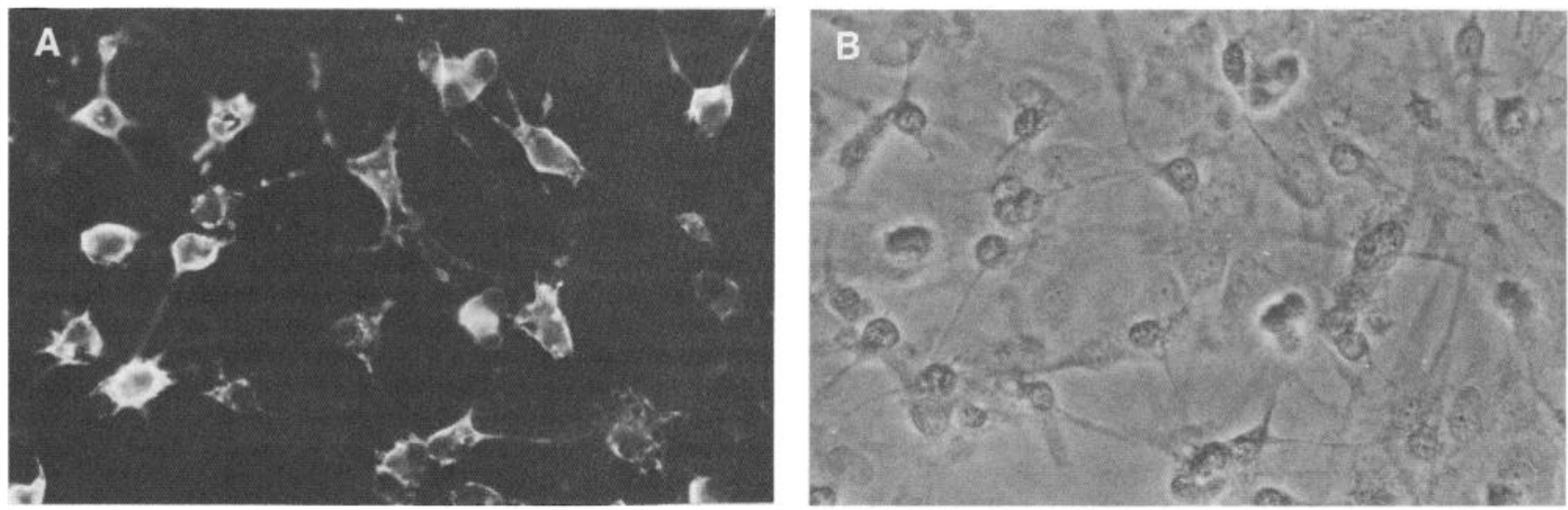

Figure 1. Rat forebrain primary culture, established at high density $\left(2.4 \times 10^{5}\right.$ cells $\left./ \mathrm{cm}^{2}\right), 7 \mathrm{~d}$ in vitro. A, Immunofluorescence photomicrograph with the anti-GD3 antibody, visualized with Rh-goat anti-mouse Ig, demonstrating that small, process-bearing cells bind the antibody. $B$, Phase contrast photomicrograph of the same field, showing many cells with large, oval nuclei and cytoplasmic processes, closely apposed to the coverslip, and a number of smaller cells growing on top. The small cells are GD3+, while the cells of the bottom layer are GD3-, but are GFAP+ (not shown, but see Fig. 2). $\times 370$.

glucose, $1 \mathrm{ml}$ glutamine $(100 \times), 1 \mathrm{ml}$ penicillin/streptomycin $(100 \times)$, and $3 \mathrm{ml} \mathrm{NaHCO}(7.5 \%)$. All sera and media solutions were purchased from Gibco, Grand Island, NY. Cells were maintained in $3 \mathrm{ml}$ (dishes) or $9 \mathrm{ml}$ (T-flasks) of medium, with a change of medium every $3 \mathrm{~d}$. For indirect immunofluorescence, cells were grown on poly-L-lysine-coated glass coverslips in $55 \mathrm{~mm}$ dishes.

\section{Antisera}

We used glial fibrillary acidic protein (GFAP) as an astrocytic marker and galactocerebroside (GC) as an oligodendrocytic marker. Properties of the rabbit anti-human GFAP, mouse monoclonal anti-GD3 (AbR24), and rabbit anti-bovine GC have been described recently (Goldman and Chiu, 1984a, for anti-GFAP; Goldman et al., 1984; Pukel et al., 1982, for anti-GD3; Norton et al., 1983, for anti-GC). In addition, we have determined that the anti-GC antiserum does not bind to SVZ cells in tissue sections of young rat $\mathrm{CNS}$.

\section{Immunofluorescence}

For indirect immunofluorescence with the GD3 antibody, live cells on coverslips were washed with PBS and incubated sequentially at $22^{\circ} \mathrm{C}$ in a diluent (PBS containing $10 \%$ fetal calf serum $/ 10 \%$ lamb serum, both heat-inactivated; Gibco) for $15 \mathrm{~min}$; mouse anti-GD3 (ascites fluid, 1:300 in diluent), $30 \mathrm{~min}$; rhodamine ( $\mathrm{Rh}$ )-conjugated goat anti-mouse Ig (1:50, Cappel Labs, Cochranville, PA), $30 \mathrm{~min}$; and fixed with $10 \%$ acetic acid in ethanol. The coverslips were washed with PBS between each step, except between the blocking serum and primary antibody incubations. For double-label immunofluorescence with the GFAP antibody, incubations were continued past the fixation step; diluent, 15 min; rabbit anti-human GFAP (1:50 in diluent), $30 \mathrm{~min}$; fluoresceinisothiocyanate (FITC)-conjugated goat anti-rabbit Ig (1:50, Cappel Labs), $30 \mathrm{~min}$. Cells were fixed with acid alcohol. For double-level immunofluorescence with anti-GD3 and anti-GC antibodies, the monoclonal antibody $(1: 300)$ and the rabbit antiserum (1:50) were mixed in diluent and applied to live cells for $30 \mathrm{~min}$. Visualization of antibody binding was accomplished with the Rh-goat anti-mouse Ig and the FITC goat anti-rabbit Ig, as described above. Coverslips were mounted with Gelvatol on glass slides and examined with a Zeiss standard microscope equipped with a substage phase condenser and with epifluorescent optics for both rhodamine and fluorescein viewing.

Cells in suspension, freshly derived from newborn rat forebrain, were stained with the anti-GD3 monoclonal antibody according to the protocol outlined above, except that incubations were performed in a $5 \mathrm{ml}$ plastic test tube and cells were centrifuged at the end of each incubation or wash and resuspended in the appropriate solution for the next step. At the end of experiments, drops of cell suspensions were placed on glass slides and coverslipped.

Controls for specificity of reactions included omission of primary antisera and the use of antisera or a monoclonal antibody which had been previously exposed to the specific antigen (Goldman and Chiu, 1984a; Goldman et al., 1984). We also determined that the FITC- conjugated goat anti-rabbit Ig did not react with the mouse monoclonal antibody, and the Rh-conjugated goat anti-mouse Ig did not bind the rabbit antibodies.

\section{Separation of GD3+ cells from cultures}

The cells growing on top of high-density cultures were isolated by a method similar to that of McCarthy and DeVellis (1980). Primary cultures were grown at an initial seeding density of $2.4 \times 10^{5} \mathrm{cells} / \mathrm{cm}^{2}$ in $75 \mathrm{~cm}^{2}$ T-flasks $\left(18 \times 10^{6}\right.$ cells per flask). On the 7 th $\mathrm{d}$ in vitro, flasks were tightly closed and transferred to a $37^{\circ} \mathrm{C}$ room, attached to an orbital shaker, and rotated at $200 \mathrm{rpm}$ overnight $(18 \mathrm{hr})$. The cells that had been shaken off were removed, the flasks washed once with $9 \mathrm{ml}$ of serum-containing medium, and the cell suspension filtered through a $25 \mu \mathrm{m}$ Nitex mesh. Cells were then collected by centrifugation and resuspended in culture medium. Cell number was determined with a hemocytometer and cells seeded onto poly-L-lysine-coated glass coverslips in (uncoated) $55 \mathrm{~mm}$ plastic dishes at $2-2.5 \times 10^{5}$ cells/dish. Coverslips were removed for immunofluorescence staining at various times after replating.

\section{Results}

In tissue sections of newborn rat hemispheres, the anti-GD3 monoclonal antibody bound to cells of the SVZ (Goldman et al., 1984). To ask whether the SVZ population could be identified in the initial cell suspensions, cells were stained with the anti-GD3 monoclonal antibody immediately after isolation from forebrain. Those that displayed a bright rhodamine fluorescence signal constituted between 6 and $10 \%$ of the total cell population.

\section{GD3 and GFAP expression in primary cultures}

Primary cultures were established at high and low densities. Although cultures under both conditions came to be composed predominantly of GFAP + cells, the appearance of the cultures was different (Goldman and Chiu, 1984a). Low-density cultures became populated primarily with flat, polygonal cells, while high-density cultures had a more complex quality. During the first few days in vitro, high-density cultures were composed of cells with a round or thin bipolar morphology. By $7 \mathrm{~d}$, a degree of stratification had taken place (Fig. $1 B$ ). A dense layer of cells closely apposed to the culture dish had emerged. These cells of the bottom layer had grown one or more cytoplasmic processes, had variable amounts of perinuclear cytoplasm flattened to the dish, and contained large, oval, relatively lucent nuclei. On top of this layer grew cells with smaller, round cell bodies. Many bore one or several thin cytoplasmic processes.

We wished to follow both the fate of SVZ cells and the development of GFAP + astrocytes, and to ask whether any of the 

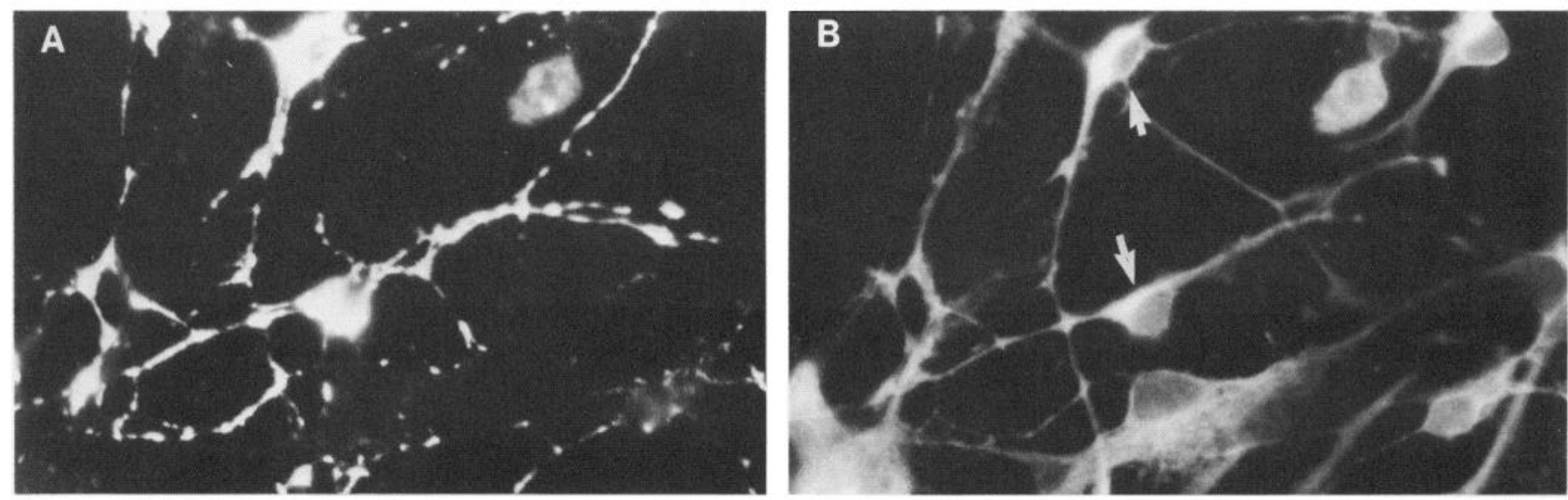

Figure 2. Double-label immunofluorescence of primary culture at $3 \mathrm{~d}$ in vitro, showing $A$, GD $3+$ cells and $B$, GFAP+ cells. Cells binding both antibodies are marked by arrowheads in $B$, but there are GD3-/GFAP+ cells. The degree of anti-GD3 antibody binding varies at this stage, with some astrocytes brightly fluorescent and others far less bright. $\times 600$.

latter population were derived from the former. Double-label immunofluorescence with the GD3 and GFAP antibodies was therefore performed from the inception of the cultures. The patterns of antibody binding went through two main stages, one during the early growth phase of the cultures, and one at later, more stable periods. At first, the proportion of cells that bound the GD3 antibody was low, in the range of 6-10\%, but increased sizably during the first few days in vitro at both high and low densities (Fig. 3, $A, C$ ). The maximal percentage was reached at about $3 \mathrm{~d}$, and declined thereafter to reach, eventually, a small proportion of total cells. During these first several days, in both high- and low-density cultures, many cells bound both the GD3 and the GFAP antibodies (Fig. 2). These double-labeled cells appeared attached to the culture dish and displayed some degree of cytoplasmic spreading. Cells which bound the GD3 antibody, but not the GFAP antiserum appeared round or bipolar and did not spread on the substrate. The GFAP+ population, which was low at first, increased so that by $3 \mathrm{~d}$ in vitro the majority of cells bound the anti-GFAP antiserum, and by $7 \mathrm{~d}$ the large majority did (Fig. 3, $A, C$ ).

After longer periods in culture, a week or more, a second pattern of antibody expression emerged. In high-density cultures, a confluent layer of cells closely attached to the plate had formed. These cells did not bind the GD3 antibody, but almost all were GFAP+, displaying cytoplasmic filamentous patterns (Fig. 5). A population of small cells resided on top of the highdensity cultures. These cells did bind the GD3 antibody (Figs. 1 and 5), giving a strong surface fluorescence which outlined cell bodies and processes. A small number of cells of the top layer bound both GFAP and GD3 antibodies (not shown), but most of the small cells appeared GFAP-. To be classified as GFAP+, a small cell had to show bright cytoplasmic fluorescence (a filamentous pattern was not discernible in such compacted cells). Positively stained processes were a clearer sign of the presence of the intermediate filament protein. In the absence of the GFAP antiserum, the FITC conjugate produced a dim, hazy fluorescent ring about the small cells in the upper layer. In low-density cultures, characterized by flat, polygonal cells, the large majority were GFAP+ (Goldman and Chiu, 1984a). A notable difference between low- and high-density cultures was that the former lacked an upper layer of small, process-bearing cells and displayed few small GD3 + cells. Thus, eventually 85$95 \%$ of cells in primary cultures of high and low densities expressed GFAP, a proportion consonant with that found in previous studies by others (Hansson et al., 1980; Manthorpe et al., 1979; Raff et al., 1979; Steig et al., 1980) and of our own (Chiu and Goldman, 1984).
The double-label immunofluorescence demonstrated that GFAP expression first arose in cells that also bound the GD3 antibody. Examination of the proportions of cells that were GD3+/GFAP-, GD3+/GFAP+, and GD3-/GFAP+ at various times revealed a profile consistent with the generation of GFAP+ cells from GD3 + cells (Fig. 3, $B, D$ ). Thus, the proportion of $+/-$ cells rose and then declined; the proportion of $+/+$ cells rose later and declined later; and eventually a group of $-1+$ cells came to be the predominant population in the cultures. These data can also be expressed as the proportion of GFAP+ cells that are also GD3+ as a function of time in culture: for example, in one experiment, this proportion was $86 \%$ at $2 \mathrm{~d}, 93 \%$ at $3 \mathrm{~d}$, and fell to $44 \%$ at $5 \mathrm{~d}$ and $18 \%$ at $8 \mathrm{~d}$. Therefore, the large majority of cells in which GFAP expression arose in vitro bore GD3 ganglioside.

In Figure 3 we have depicted proportions of total cells binding GD3 or GFA antibodies, rather than numbers of cells. Forebrain primary cultures at high density increase in cell number between 3 and $12 \mathrm{~d}$, reaching a stable cell number by 14-16 d (Chiu and Goldman, 1984). Numbers of cells in high-density cultures that bind anti-GD3 or GFAP antibodies have been counted (Fig. 4). Such counts indicate that the majority of cells in the initial suspension do not survive in primary culture. There is an increase in the number of GD3+/GFAP+ cells in the 1st week, and a subsequent fall in the number of double-labeled cells. There is a large increase in the number of GD3-/GFAP+ cells in the 2nd week. GD3 + cells increase, but not to a major extent. Interpretations of cell proliferation are difficult, however, without thymidine labeling. Several processes are occurring in culture: increases in GD3 + cells through proliferation, and decreases in GD3 + cells both through cell death and through loss of the ganglioside as GD3-/GFAP+ cells form. Cultures at low density either do not grow appreciably, or grow slowly, doubling cell number in a week, for example (Goldman and Chiu, 1984a, b). In low-density cultures, therefore, there is little net cell growth either during the period in which the proportion of GFAP+ cells is increasing or when the proportion reaches a stable, high value.

\section{GD3 and GC expression in primary culture}

Several investigators have described oligodendrocytes in primary culture from neonatal rodent brain (Bologa-Sandru et al., 1981; Labourdette et al., 1979; Raff et al., 1979) and have shown that they grow as small, process-bearing cells on top of a confluent cell monolayer. To ask whether cells with the oligodendrocyte marker, GC, might have originated from GD3+ cells, we performed double-label immunofluorescence with anti-GC 
A

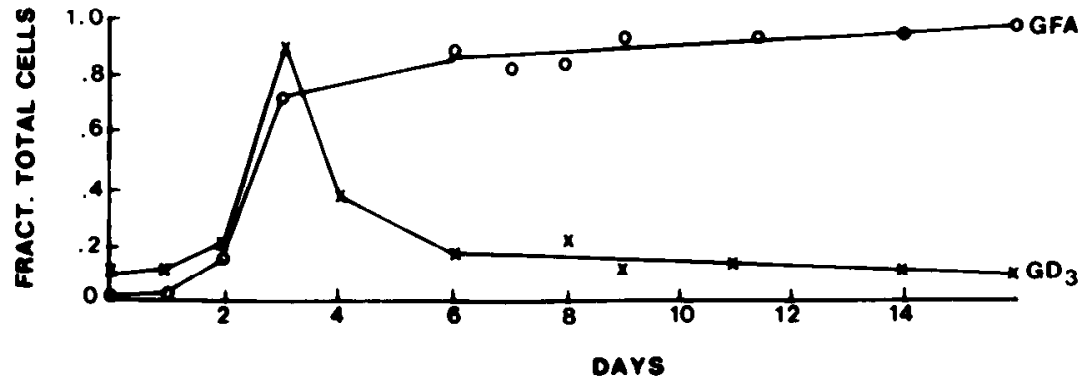

B

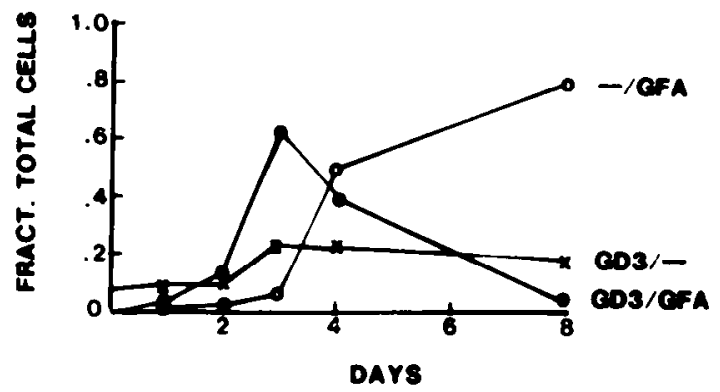

C

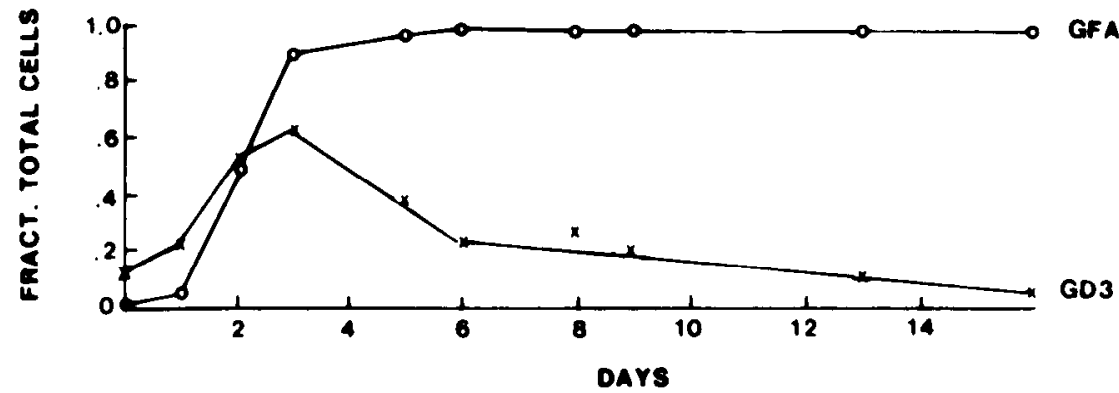

D

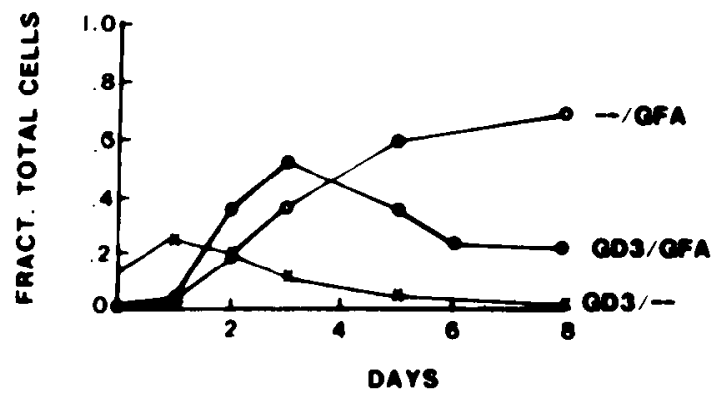

Figure 3. Time course of expression of GD3 and GFAP in primary cultures established at $A, B$, high density $\left(2.4 \times 10^{5}\right.$ cells $\left./ \mathrm{cm}^{2}\right)$ and $C, D$, low density $\left(0.4 \times 10^{5}\right.$ cells $\left./ \mathrm{cm}^{2}\right) . A, C$, Ordinate represents the fraction of total cells that bound either the GD3 or GFAP antibodies. $B, D$, Ordinate represents the fraction of total cells in double-label experiments that bound only the anti-GD3 antibody (GD3/ - -), only the GFAP antiserum (- -/GFAP), or both (GD3/GFA). Immunofluorescence was performed on cells grown on coverslips. Each point represents the average of at least two experiments, with at least two coverslips counted/point/experiment and 150-300 cells (for low-density cultures) or 400-600 cells (high-density cultures) counted/coverslip. and anti-GD3 antibodies at various times after the beginning of high-density primary cultures. GC+ cells were detected as a population of small cells, growing on top of the astrocytic monolayer. While little GC antiserum binding was detected after $7 \mathrm{~d}$, GC expression was readily observed by $2-3$ weeks (Fig. 6). All $\mathrm{GC}+$ cells at $14 \mathrm{~d}$ were also GD3 +, although there were $\mathrm{GC}-1$ GD3 + cells present. By $30 \mathrm{~d}$ in vitro, the longest period we examined, GC+ cells still bound the GD3 antibody. By this time, the large majority of the GD3 + cells were also GC+. We have not observed GD3-/GC+ process-bearing cclls, at lcast up to $30 \mathrm{~d}$ in vitro. The proportion of $\mathrm{GC}+$ cells in high-density cultures varied somewhat from culture to culture, but ranged from 5 to $9 \%$. In contrast to the high-density cultures, few GC+ cells were observed in cultures established at low density and stained at 7,14 , and $21 \mathrm{~d}$ in vitro.

Isolation and subculture of GD3+ cells

Our results have indicated that the small, GD3+ process-bearing cells of the top layer eventually develop an oligodendrocytic characteristic if left in place. We examined whether these same cells would still become oligodendrocytic if removed from the astrocytc monolayer and maintained separately in the same culture medium. The localization of GD3 to cells in the top layer of the high-density cultures suggested that we could isolate these 


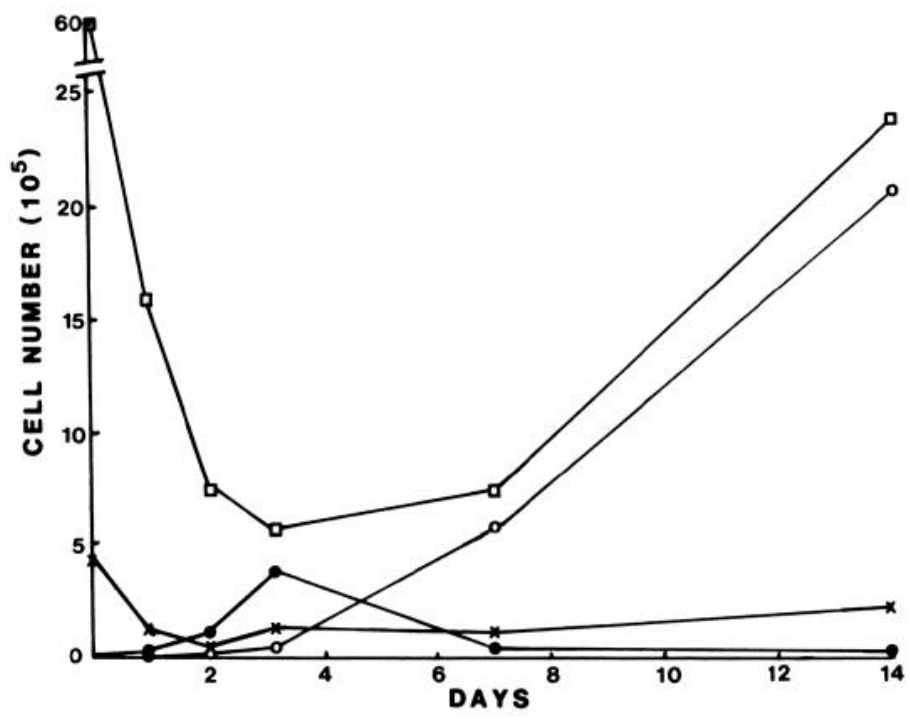

Figure 4. Time course of GD3 and GFAP expression in primary culture established at high density $\left(2.4 \times 10^{5}\right.$ cells $/ \mathrm{cm}^{2}=6 \times 10^{6}$ cells $/ 55$ $\mathrm{mm}$ dish) showing numbers of cells as a function of time in vitro. The ordinate represents total $(\square)$ cells/dish, those that bound only the GD3 antibody (GD3/- -; $x$ ), only the GFAP antiserum (- -/GFA; 0 ), or both (GD3/GFA; $\bullet$ ). Immunofluorescence and counting on coverslips were performed as described in Materials and Methods and Figure 3.

cells by mechanical means. We followed the method of McCarthy and DeVellis (1980), who isolated a population of cells from dense primary cultures by rotary shaking. After the 7 th $\mathrm{d}$ in vitro, flasks were shaken overnight and the dislodged cells collected and placed in culture at $2-2.5 \times 10^{5}$ cells $/ 55 \mathrm{~mm}$ dish in our usual growth medium, containing $20 \%$ fetal calf serum. The cells attached readily to the polylysine coating and within $24 \mathrm{hr}$ had produced one or several cytoplasmic processes (Fig. 7). By 3-4 d, they had elaborated more processes, which grew radially and branched, giving the cultures a background of a fine filamentous network (Fig. 8). The morphology of these cells appeared qualitatively similar to that described by McCarthy and DeVellis (1980) and bore a similarity to oligodendrocytes isolated from more mature brain and maintained in vitro (Norton et al., 1983). With longer times, some of the cells began to spread out, with a sheet of cytoplasm forming between processes. Eventually, cells with a flat, polygonal morphology, as well as those with a stellate, process-bearing shape, were observed (Figs. 9 and 10).

Immunofluorescence analysis revealed that all of the shaken and subcultured cells initially bound the GD3 antibody (Figs. 7 and 11). Thus, this method successfully separates out a population of cells distinguished by their expression of a ganglioside characteristic of immature cells. A small proportion also showed a cytoplasmic signal with the GFAP antiserum (Fig. 11). Within $3 \mathrm{~d}$, however, the proportion of GD3 +/GFAP + cells had increased and that of the GD3+/GFAP - cells declined, with apparently inverse kinetics (Fig. 11). At this point, GFAP was detected in the stellate, highly branched cells (Fig. 8). Thus, as in the primary culture, GFAP first became detectable in cells already bearing GD3 ganglioside. In some cells, at this point the GFAP fluorescence appeared primarily juxtanuclear (Fig. 8 ), with fluorescence detected in one or more, but not necessarily all of the thin cytoplasmic processes. Eventually a population of GD3 - /GFAP + cells became appreciable, but lagged behind the appearance of the $+/+$ population (Fig. 11). This $-/+$ population was composed of flat cells with round or polygonal borders (Fig. 9). Flat cells labeled with both antibodies were also seen, however (Fig. 9). In contrast to the flat cell population, process-bearing astrocytes remained GD3 + (Fig. 10), with few exceptions.

Subcultures were also stained with the anti-GC antibody over the course of several weeks after subculture. In three experiments, $1 \%$ or fewer of the cells bound the anti-GC antibody. We did not find cells which bound both anti-GFAP and antiGC antibodies.

We have counted cell number in cultures shaken and replated at this moderately low density and have found that the replating efficiency lies between 30 and $40 \%$. The cell number remains unchanged over the course of our experiments. Thus, subculturing does not select for a very small population of the GD3+ cells and there is no net cell growth in subcultures.

\section{Discussion}

The use of an anti-GD3 monoclonal antibody, which binds to cells of CNS germinal zones, has enabled us to follow the fate of SVZ cells in culture. We have found that many germinal zone cells acquire an astrocytic characteristic within a few days. Double-label experiments with antibodies to GD3 and GFAP indicate that the astrocyte intermediate filament protein is first detected in cells which express GD3 ganglioside. Eventually GD3 expression is lost in many of these cells, since the predominant cell population after more than a week is GD3-/
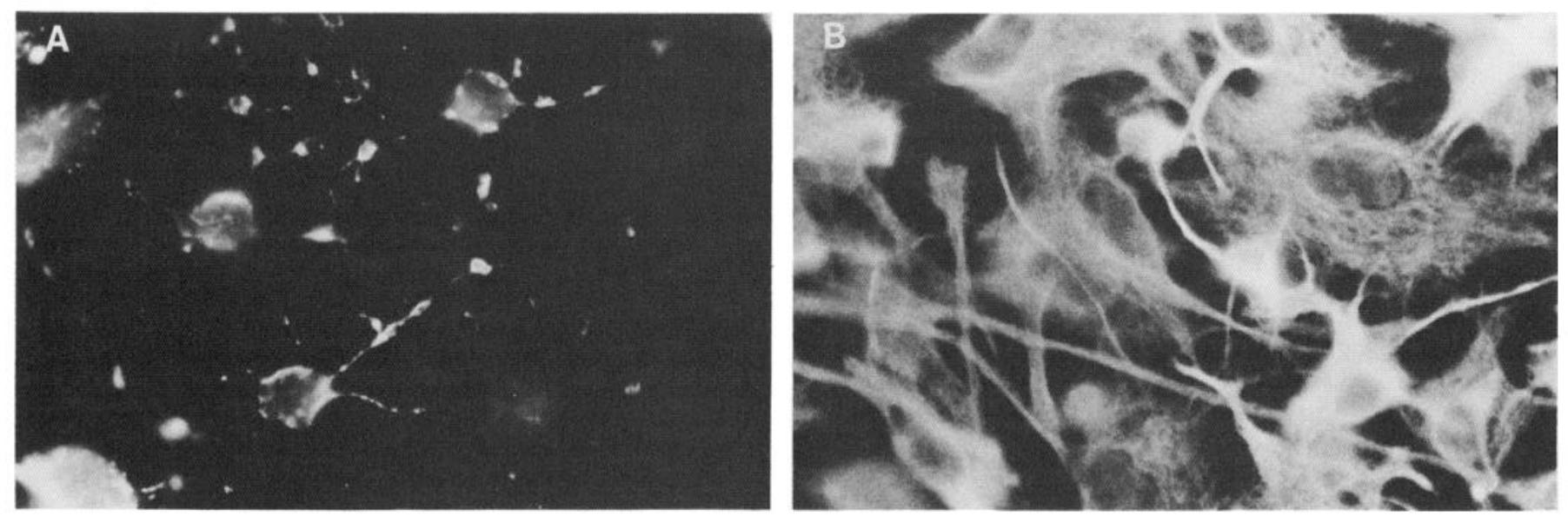

Figure 5. Double-label immunofluorescence of high-density culture. $A$, Process-bearing cells on top bind the anti-GD3 antibody, visualized with Rh-goat anti-mouse Ig. $B$, Cells of the bottom layer of the same field bind the anti-GFAP antiserum, visualized with FITC goat anti-rabbit Ig. $\times 600$. 

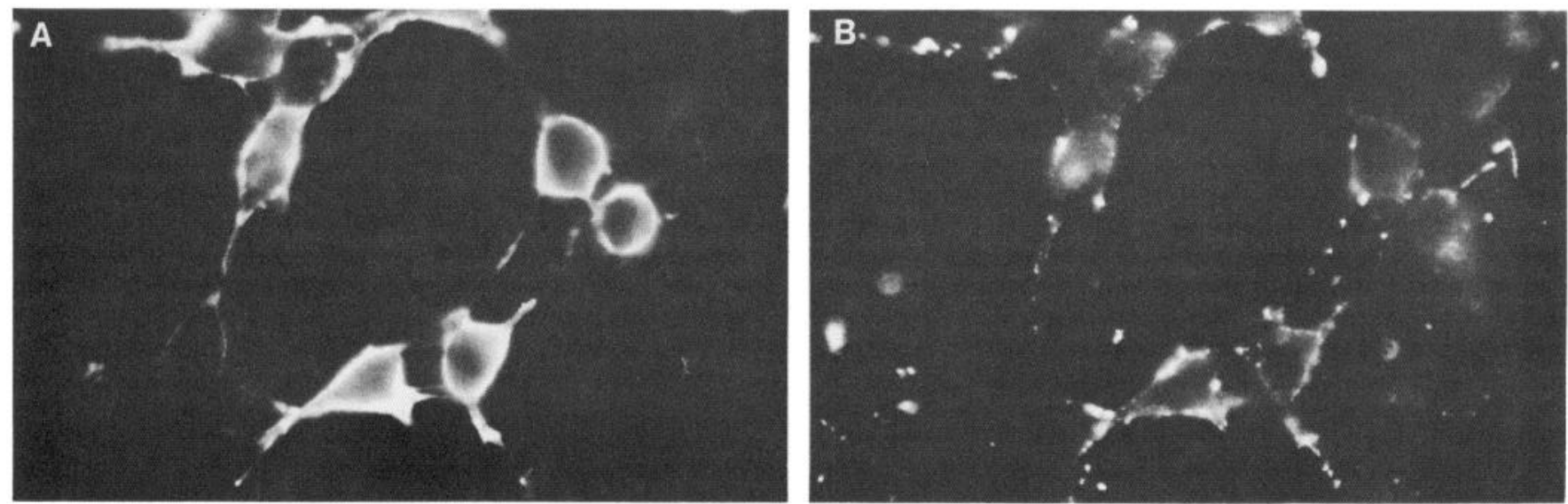

Figure 6. Double-label immunofluorescence of primary culture at $28 \mathrm{~d}$ in vitro. A, Process-bearing cells still bind the anti-GD3 antibody, visualized with Rh-goat anti-mouse Ig. $B$, The same cells also bind the anti-GC antiserum, visualized with FITC goat anti-rabbit Ig. Anti-GC binding varies from cell to cell, with those at the right binding the antibody relatively poorly. $\times 600$.
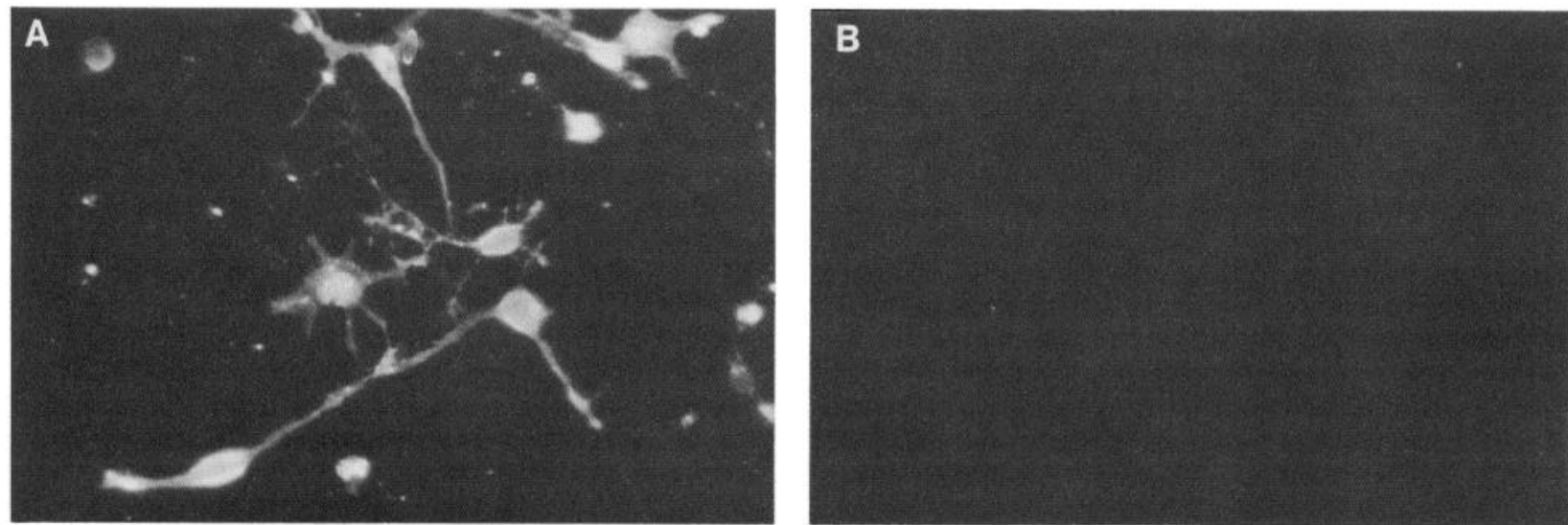

Figure 7. Double-label immunofluorescence of subcultured cells $1 \mathrm{~d}$ after replating. $A$, Anti-GD3 antibody and $B$, anti-GFAP antiserum. $\times 590$.
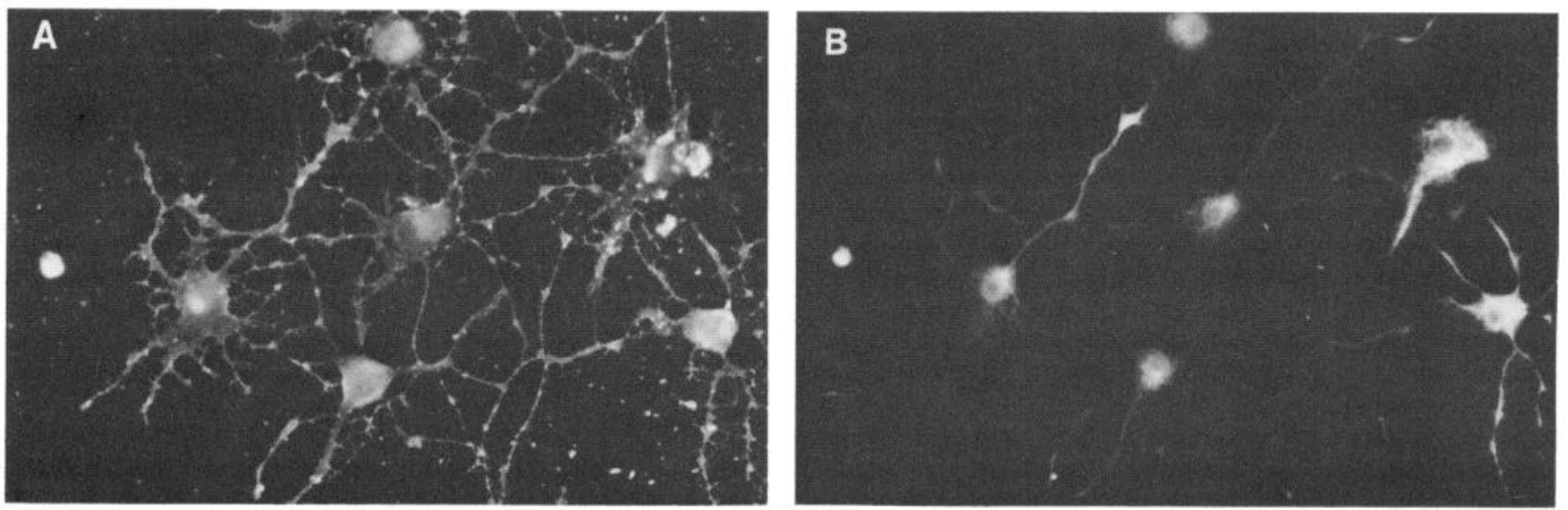

Figure 8. Double-label immunofluorescence of subcultured cells $3 \mathrm{~d}$ after replating. The stellate cells with radial processes bind both $A$, anti-GD3 antibody and $B$, anti-GFAP antiserum. Detectable GFAP fluorescence begins in juxtanuclear zone. In many of these cells, GFAP fluorescence is not visible in all processes. $\times 590$.

GFAP+. This loss of GD3 appears to be similar to what is found in vivo. That is, GD3-antibody binding was not detected in the cerebral cortex or in the subcortical white matter of adult rats (Goldman et al., 1984). Furthermore, in our previous studies, based on immunofluorescence methodology, we did not observe GD3 +/GFAP + cells in developing white matter.

The increase in the proportion of GD3 + cells between Day 1 and Day 3 (Fig. 3) is likely due to a disproportionate loss of
GD3 - cells (and the disproportionate survival of GD3 + cells) during the first few days, although cell counts demonstrate some loss of GD3 + cells as well. Primary cultures from newborn rodent forebrain typically have a low initial plating efficiency: on the order of $5-10 \%$ of the cells in the initial suspension are found in culture after $3 \mathrm{~d}$ in vitro. The vast majority of neurons do not survive under these culture conditions [there are small numbers of cells bearing neuronal markers in cultures from 

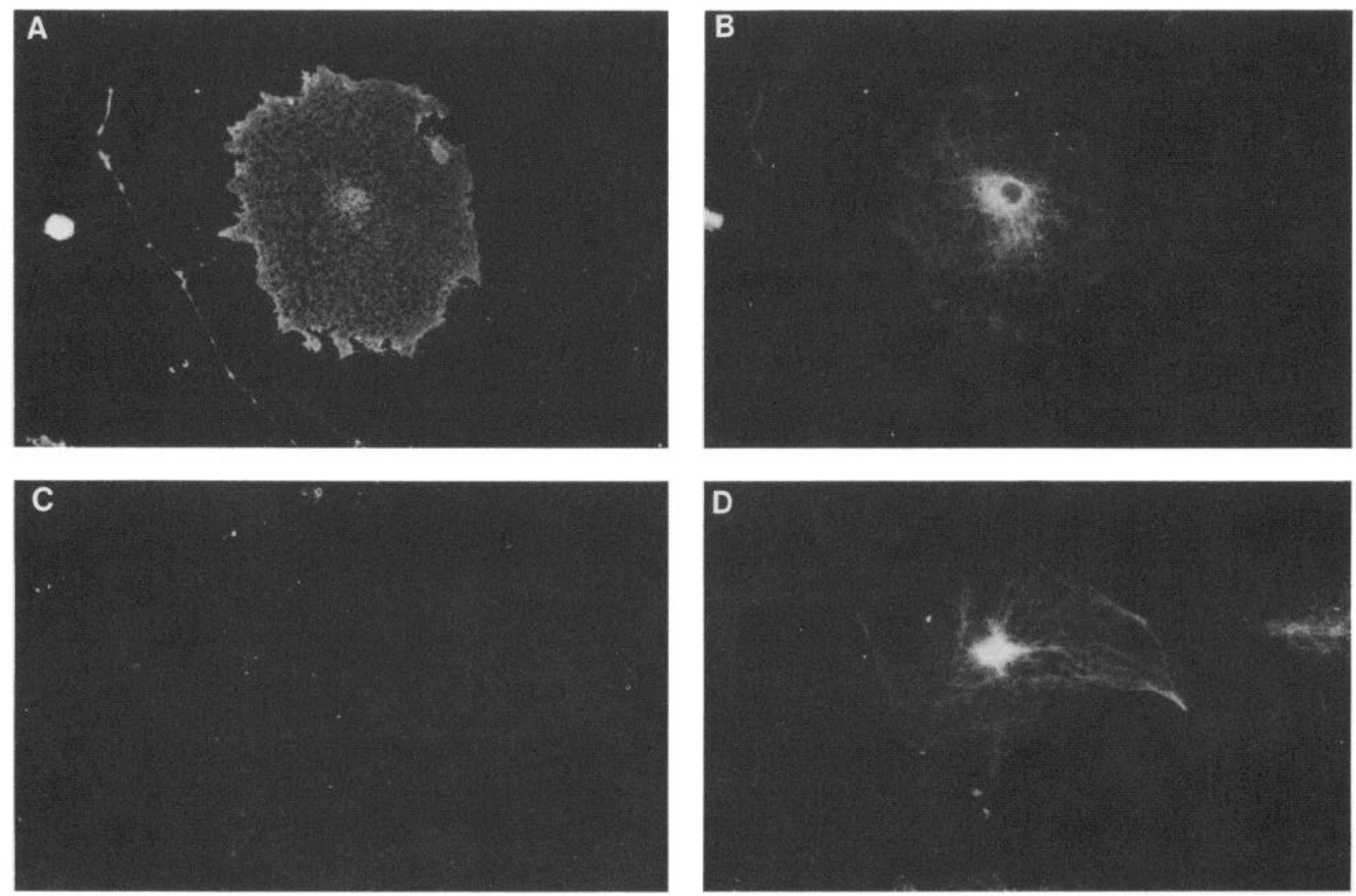

Figure 9. Double-label immunofluorescence of flat cells in subcultures, showing an example of one that was $A$, GD3+ and $B$, GFAP+ and one that was $C$, GD3 - and $D$, GFAP.$+ \times 590$.

newborn rat forebrain (Raff et al., 1979)]. Furthermore, we have not maintained cultures under conditions that can enhance neuronal survival and suppress glial proliferation, such as the presence of FUdR or high concentrations of $\mathrm{KCl}$ (Raff et al., 1979).

Double-label experiments with GC and GD3 antisera demonstrated that GC+ cells also arise from GD3 + cells. The kinetics of astrocytic and oligodendrocytic differentiation appear to be different, with astrocytes appearing earlier in the life of the cultures than oligodendrocytes. This lag in appearance between that of the two major glial cell types in primary cultures and the analogy to gliogenesis in vivo has been noted (Abney et al., 1981).

That primary cultures from neonatal rat forebrain are heterogeneous has been recognized in many studies (Bologa-Sandru et al., 1981; Hansson et al., 1981; Labourdette et al., 1979; Manthorpe et al., 1979; Steig et al., 1980). Previous work has pointed out the presence of such elements as oligodendrocytes and macrophages, although all concur that the large majority of cells are astrocytic. What has not been heretofore demonstrated, however, is that such primary cultures contain an immature cell population, derived from the subventricular germinal zone, and that these cells give rise to both astrocytes and oligodendrocytes. A population of cells-those that grow on top of an astrocytic monolayer-continues to express GD3 ganglioside. Since there are GD3+/GC - cells, at least for several weeks, among this population, it is possible that the continued presence of such immature cells could explain the renewed generation of oligodendrocytes in primary culture after all GC+
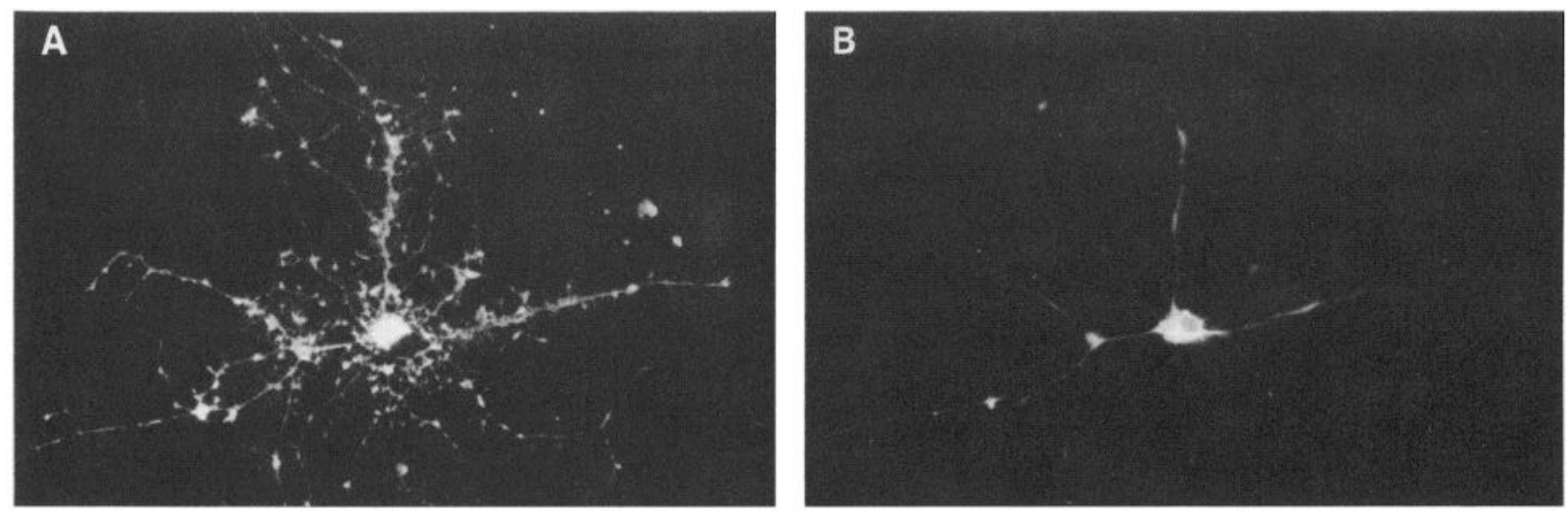

Figure 10. Double-label immunofluorescence of $A, B$, highly branched cell that is both $A, \mathrm{GD} 3+$ and $B, \mathrm{GFAP}+. \times 590$. 
cells have been eliminated by complement-dependent lysis (Bologa et al., 1984). Immature cells may also be the source of "transformed" lines established from neonatal CNS (Bressler et al., 1983).

Since the GD3 + cells reside in an upper layer of the cultures, we attempted to isolate these cells by mechanical means and found that essentially all cells dislodged by rotary shaking were GD3 + . Such an experiment was of interest for scveral reasons. It can be difficult in high-density cultures to be certain of a positive GFAP reaction in small, compact cells sitting atop a monolayer of GFAP + cells. Subculturing the shaken cells at a somewhat lower density allowed a clearer determination of GFAP expression. In fact, GFAP was not detectable by immunofluorescence in the majority of cells (about $80 \%$ ) $18 \mathrm{hr}$ after shaking and subculture. The large majority, however, begin to express GFAP within a few days. This experiment was also performed to examine the developmental potential of these cells, and indicated that the GD3 +/GFAP - cells do not represent a subclass of immature cells that has become committed to an oligodendrocytic lineage. While they eventually express GC and not GFAP if left in primary culture, they will become astrocytic if subcultured at low density in the same medium.

The previous characterization of the cells shaken off highdensity cultures as oligodendrocytes (McCarthy and DeVellis, 1980) should therefore be reexamined, particularly if subcultures are carried out in a serum-containing medium. Although the cells with thin, radially oriented processes appear oligodendrocytic, the large majority come to express GFAP within a few days in the presence of $20 \%$ fetal calf serum. Rather than being oligodendrocytes, these cells appear to be immature, derived proximately from the germinal zone, whose developmental fates have not yet been determined. We do not yet know whether each germinal zone cell is pluripotent, although the fact that the large majority express GC under primary culture conditions and GFAP in subculture would argue strongly that these germinal zone cells are bipotential. We also do not yet know when and if specific glial differentiation becomes irreversibly determined.

Ultrastructural characterization of these cells during early stages of subculture might demonstrate only a few, if any, intermediate filaments. Furthermore, examination of cell processes might disclose few filaments, since it appeared from immunofluorescence that not all of the processes contained GFAP, particularly the fine ones. The apparent absence of GFAP in some processes may simply reflect the method's limits of sensitivity, but it may reflect a nonhomogeneous distribution of intermediate filaments during the early stages of GFAP expression.

GFAP expression in subculture was accompanied by changes in cell shape, from a round morphology with thin processes to either flat or stellate forms, closely apposed to the culture dish. Such forms may be analogous to the distinction Raffet al. (1983a) have drawn between the stellate "Type 2" astrocytes that bind a monoclonal antibody, A2B5, and flat "Type 1" astrocytes that do not bind A2B5. GD3 ganglioside itself does not appear to be useful in distinguishing different morphological phenotypes of astrocytes. Although GD3-/GFAP+ cells were of the flat variety and most GD3 +/GFAP + cells were stellate, there were some flat cells labeled with both antibodies, at least up to $8 \mathrm{~d}$ post-subculture. Perhaps distinctions would be clearer after longer times. The presence, or absence, of GD3 ganglioside may well confer important characteristics to astrocytes and other cells, but it is not known what these might be.

The stimuli that induce astrocytic or oligodendrocytic differentiation of germinal zone cells are not known. There is evidence that serum promotes astrocytic differentiation from immature cells in vitro. Thus, Raff et al. (1983b) found in cultures from young mouse optic nerve that cells that bound the A2B5 monoclonal antibody expressed GFAP in the presence of fetal calf

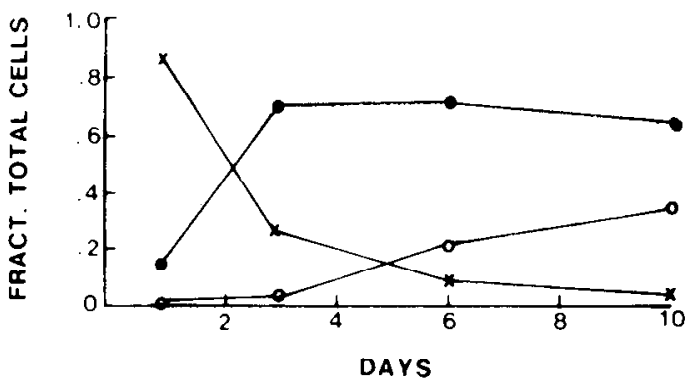

Figure 11. Time course of expression of GD3 and GFAP in subcultures. Cells were shaken off primary cultures after $7 \mathrm{~d}$ and subcullured for various times before immunofluorescence was performed to determine the fraction of cells that bound the anti-GD3 antibody only (GD3/- -; $x$ ), the GFAP antiserum only (- - /GFA; O) or both (GD3/ GFA; ). Each point represents the average of two experiments, with two coverslips counted/point/experiment and 100-300 cells counted/ coverslip.

serum. Fischer et al. (1982) cultured a GFAP- population of cells from early postnatal mouse cerebellum in the presence of serum-free medium. The addition of $10 \%$ horse serum induced GFAP expression, determined by immunofluorescence. Preliminary reports from several laboratories (Ingraham and McCarthy, 1984; Poduslo et al., 1984; Saneto et al., 1984) have noted that the population of cells shaken off primary forebrain cultures varies in the proportions of cells with oligodendrocytic or astrocytic qualities, depending on culture medium. In our experiments, GD3 + cells became predominantly astrocytic in the presence of $20 \%$ fetal calf serum. We have also examined properties of dislodged cells subcultured in different media. While few GC + cells appear in $20 \%$ fetal calf serum, many appear in $5 \%$ serum. Furthermore, serum-free, chemically defined media prevent the expression of GFA in the GD3 + cells (unpublished observations). Serum is unlikely to be the only contributing factor in determining glial differentiation from germinal zone cells in primary culture, however. The continued presence of GD3 + /GFAP - cells and their development of an oligodendrocytic character in high-density cultures grown in serum indicates that GD3 + cells do not necessarily become GFAP + in serum and indicates that other factors are at work. The lag period between the generation of astrocytes and that of oligodendrocytes in the high-density cultures suggests that oligodendrocytic differentiation from immature cells may depend upon interaction of such immature cells with astrocytes. One could envision a cell surface interaction or an astrocytic product promoting the acquisition of oligodendrocytic characteristics. The presence and type of such interactions can be tested experimentally.

The small, process-bearing cells that grow on top of the astrocyte monolayer are A2B5+ (Walker et al., 1984, and our unpublished observations), while cells of the astrocyte layer are A2B5-. Cells shaken off the top layer and subcultured in serum become astrocytic (see above) and many retain the ability to bind A2B5 (unpublished observations). Thus, GD3 + cells can give rise in culture to both A2B5- (Type 1) and A2B5+ (Type 2) astrocytes. These observations suggest that the GD3 + stage represents a developmental period earlier than that characterized by A2B 5 antibody binding.

Our results in no way suggest that all astrocytes in postnatal rat forebrain are immediately derived from SVZ cells. The glia that have established subpial connections and become GFAP+ in the first several postnatal days presumably originate from radial glia that were established some time previously and subsequently lost their ventricular attachments, a transformation that has been followed in monkcy telencephalon, where radial glia are GFAP+ (Livett and Rakic, 1982). Some of the astrocytes of the subcortical white matter also may be derived from radial 
glia. In rodent forebrain, radial glia are not GFAP+, however. Thus, using GFAP as an astrocyte marker is a limited criterion for astroglial phenotype. That is, GFAP-radial glia may have other, as yet unknown, qualities in common with GFAP+ glia. In forebrain cultures, nevertheless, it appears that the large majority of GFAP + cells develop from GD3 + cells. Such differentiation may thus not accurately reflect the fate of the SVZ cell population present at birth. Our results and those of others (Raff et al., 1983b) may rather reflect the developmental potential of $\mathrm{SVZ}$ cells, a potential that can be manipulated in vitro. The isolation of a SVZ cell population can, in future studies, be used to great advantage to define molecular characteristics of these immature cells and also to probe stimuli that result in differentiation along either astrocytic or oligodendrocytic lines.

\section{References}

Abney, E. R., P. P. Bartlett, and M. C. Raff (1981) Astrocytes, ependymal cells, and oligodendrocytes develop on schedule in dissociated cell cultures of embryonic rat brain. Dev. Biol. 83: 301-310.

Altman, J. (1966) Proliferation and migration of undifferentiated precursor cells in the rat during postnatal gliogenesis. Exp. Neurol. 16: 263-278.

Bologa, L., A. Z'graggen, and N. Herschkowitz (1984) Proliferation rate of oligodendrocytes in culture can be influenced by extrinsic factors. Dev. Neurosci. 6: 26-31.

Bologa-Sandru, L., H. P. Siegrist, A. Z'graggen, K. Hofmann, U. Wiesmann, D. Dahl, and N. Herschkowitz (1981) Expression of antigenic markers during the development of oligodendrocytes in mouse brain cell cultures. Brain Res. 210: 217-229.

Bressler, J. P., R. Cole, and J. DeVellis (1983) Neoplastic transformation of newborn rat oligodendrocytes in culture. Cancer Res. 43: 709-715.

Chiu, F.-C., and J. E. Goldman (1984) Synthesis and turnover of cytoskeletal proteins in cultured astrocytes. J. Neurochem. 42: 166174

Fischer, G., A. Leutz, and M. Schachner (1982) Cultivation of immature astrocytes of mouse cerebellum in a serum-free, hormonallydefined medium. Appearance of the mature astrocytic phenotype after addition of serum. Neurosci. Lett. 29: 297-302.

Goldman, J. E., and F.-C. Chiu (1984a) Growth kinetics, cell shape, and the cytoskeleton of primary astrocyte cultures. J. Neurochem. 42: 175-184.

Goldman, J. E., and F.-C. Chiu (1984b) Dibutyryl cyclic AMP causes intermediate filament accumulation and actin reorganization in primary astrocytes. Brain Res. 306: 85-95.

Goldman, J. E., M. Hirano, R. K. Yu, and T. N. Seyfried (1984) GD3 ganglioside is a glycolipid characteristic of immature neuroectodermal cells. J. Neuroimmunol. 7: 179-192.

Hansson, E., A. Sellstrom, L. I. Persson, and L. Ronnback (1980) Brain primary culture-a characterization. Brain Res. 188: 233-246.

Imamoto, K., J. A. Paterson, and C. P. Leblond (1978) Radiographic investigation of gliogenesis in the corpus callosum of young rats. 1. Sequential changes in oligodendrocytes. J. Comp. Neurol. 180: 115138.

Ingraham, C. A., and K. D. McCarthy (1984) Oligodendroglial cell differentiation: Effects of culture conditions. Trans. Am. Soc. Neurochem. 15: 110.

Labourdette, G., G. Roussel, M. S. Ghandour, and J. L. Nussbaum (1979) Cultures from rat brain hemispheres enriched in oligodendrocyte-like cells. Brain Res. 179: 199-203.

Livett, P., and P. Rakic (1980) Immunoperoxidase localization of glial fibrillary acidic protein in radial glial cells and astrocytes of the developing rhesus monkey brain. J. Comp. Neurol. 193: 815-840.

Manthrope, M., R. Adler, and S. Varon (1979) Development, reactivity and GFA immunofluorescence of astroglia-containing monolayer cultures from rat cerebrum. J. Neurocytol. 8: 605-621.

McCarthy, K. D., and J. DeVellis (1980) Preparation of separate astroglial and oligodendroglial cell cultures from rat cerebral tissue. J. Cell Biol. 85: 890-902.

Norton, W. T., M. Faroog, K. L. Fields, and C. S. Raine (1983) The long term culture of bulk-isolated bovine oligodendroglia from adult brain. Brain Res. 270: 295-310.

Poduslo, S. E., K. Miller, R. Curbeam, and P. Reier (1984) Purification and characterization of cultures of oligodendroglia from rat brain. Soc. Neurosci. Abstr. 10: 765 .

Privat, A., and C. P. Leblond (1972) The subependymal layer and neighboring region in the brain of the young rat. J. Comp. Neurol. 146: 277-302

Pukel, C. S., K. O. Lloyd, L. R. Travassos, W. G. Dippold, H. F. Oettgen, and $L$. J. Old (1982) $\mathrm{G}_{\mathrm{D} 3}$, a prominent ganglioside of human melanoma. J. Exp. Med. 155: 1133-1147.

Raff, M. C., K. L. Fields, S.-I. Hakomori, R. Mirsky, R. M. Pruss, and J. Winter (1979) Cell-type-specific markers for distinguishing and studying neurons and the major classes of glial cells in culture. Brain Res. 174: 283-308.

Raff, M. C., E. R. Abney, J. Cohen, R. Lindsay, and M. Noble (1983a) Two types of astrocytes in cultures of developing rat white matter: Differences in morphology, surface gangliosides, and growth characteristics. J. Neurosci. 3: 1289-1300.

Raff, M. C., R. H. Miller, and M. Noble (1983b) A glial progenitor cell that develops in vitro into an astrocyte or an oligodendrocyte depending on culture medium. Nature 303: 390-396.

Saneto, R. P., R. Cole, and J. DeVellis (1984) Proliferation and characterization of isolated oligodendrocytes cultured in a chemically defined medium. Soc. Neurosci. Abstr. 10: 369.

Steig, P. E., H. K. Kimelberg, J. E. Mazurkiewicz, and G. A. Banker (1980) Distribution of glial fibrillary acidic protein and fibronectin in primary astroglial cultures from rat brain. Brain Res. 199: 493500.

Temple, S., and M. C. Raff (1985) Differentiation of a bipotential glial progenitor cell in single cell microculture. Nature 313:223-225.

Walker, A. G., J. Chapman, C. B. Bruce, and M. G. Rumsby (1984) Immunocytochemical characterization of cell cultures grown from dissociated 1-2 day post-natal rat cerebral tissue. J. Neuroimmunol. 7: $1-20$. 